\title{
The Role of the Ferric Uptake Regulator (Fur) in Regulation of Helicobacter pylori Iron Uptake
}

\author{
Arnoud H. M. van Vliet, ${ }^{*}, \dagger$ Jeroen Stoof,* Ronald Vlasblom, † Stuart A. Wainwright, $\ddagger$ Nicola J. Hughes, $\neq$ \\ David J. Kelly, $\ddagger$ Stefan Bereswill,§ Jetta J. E. Bijlsma, † Theo Hoogenboezem, đ Christina M. J. E. \\ Vandenbroucke-Grauls, † Manfred Kist, Ernst J. Kuipers* and Johannes G. Kusters* \\ *Department of Gastroenterology and Hepatology, Erasmus MC, Rotterdam, The Netherlands; †Department of Medical \\ Microbiology and Infection Control, VU University Medical Center, Amsterdam, The Netherlands; $\neq$ Department of Molecular \\ Biology and Biotechnology, University of Sheffield, Sheffield, UK; \$Department of Medical Microbiology and Hygiene, Institute of \\ Medical Microbiology and Hygiene, University Hospital of Freiburg, Freiburg, Germany; and IDepartment of Pediatrics, Erasmus \\ MC, Rotterdam, The Netherlands
}

\begin{abstract}
A B S T RACT
Background. Availability of the essential nutrient iron is thought to vary greatly in the gastric mucosa, and thus the human gastric pathogen Helicobacter pylori requires regulatory responses to these environmental changes. Bacterial iron-responsive regulation is often mediated by Ferric Uptake Regulator (Fur) homologs, and in this study we have determined the role of $H$. pylori Fur in regulation of $H$. pylori iron uptake.
\end{abstract}

Methods. Wild-type H.pylori and fur mutant derivatives were compared after growth in ironrestricted and iron-replete conditions. Iron-uptake was measured using ${ }^{55} \mathrm{Fe}$-labeled iron, whereas gene expression was monitored at the transcriptional level using Northern hybridization and lac $Z$ reporter gene fusions.

Results. Iron-uptake and total cellular iron content were approximately five-fold increased in the fur mutant compared with the wild-type strain, which indicated that in the fur mutant iron-uptake is not repressed by excess iron. A comprehensive screening of all $H$. pylori genes encoding putative iron-uptake proteins indicated that some of these $H$. pylori genes are constitutively expressed, while others are ironand Fur-regulated.

Conclusions. Iron uptake in H.pylori is in part differently regulated compared with other bacteria, since in $H$. pylori some iron-uptake systems are constitutively expressed. However, other iron uptake systems of $H$.pylori display the iron- and Fur-mediated repression that is common in bacteria. Taken together, this Fur-mediated modulation of iron-uptake capacity may be a specific adaptation to the conditions in the human stomach, where iron starvation and iron overload can be encountered in relatively short time intervals.

Keywords. Iron uptake, transcription, gene regulation, Fur.
$\mathrm{I}^{\mathrm{r}}$ ron is an essential element for almost all living organisms, as it is a cofactor required for activity of many enzymes, and acts as a catalyst in electron transport processes. However, in the presence of oxygen, iron catalyzes the formation of toxic oxygen radicals [1]. Therefore intracellular iron homeostasis is of critical importance to all cells, and in most bacteria this is mediated by the Ferric Uptake Regulator protein Fur [2]. This repressor down-regulates transcription of

Reprint requests to: Arnoud H. M. van Vliet, Department of Gastroenterology and Hepatology, Room L-481, Erasmus MC, Rotterdam, The Netherlands, Email: vanvliet@mdl.azr.nl. iron transport systems when the intracellular concentration of $\mathrm{Fe}^{2+}$ exceeds a certain level. The iron-responsive regulation is mediated by iron-dependent binding of the Fur protein to conserved DNA sequences (Fur boxes) located in the promoters of iron-regulated genes [2]. Fur homologs are present in both gram-negative and gram-positive bacteria, and besides their functions in iron homeostasis they are also involved in the regulation of additional metabolic processes, for example oxidative stress defense or acid resistance [2-4].

Helicobacter pylori is a gram-negative, microaerophilic bacterial pathogen, which colonizes the mucosal layer overlying the gastric epithelium 
of the human stomach. The presence of $H$. pylori in the gastric mucosa is associated with chronic active gastritis, which can develop in peptic ulcer disease and atrophic gastritis, an important precursor of gastric cancer [5]. Approximately half of the world's population is colonized by $H$. pylori, and the infection is therefore considered an important public health problem, with serious economic consequences [5].

In its natural niche, $H$. pylori is thought to encounter great variations in the iron concentration in the human stomach. Significant amounts of iron and heme compounds can be released from food by peptic degradation, or from gastric epithelial cells as a result of the H.pylorimediated inflammatory response, while periods of iron-restriction may also be encountered since lactoferrin chelates iron at the mucosal surface [6]. The bioavailability of iron also depends on the oxidation state, which in turn is affected by the $\mathrm{pH}$ and oxygen tension of the environment [7]. Since H. pylori is capable of long-term colonization of the gastric mucosa, the bacterium is clearly able to respond to important environmental changes like iron availability. The H. pylori genome sequence contains a multitude of genes predicted to function in iron uptake [8-10]. However, experimental evidence for their function in iron transport is lacking, except for the FeoB ferrous iron transporter [11].

As most bacteria, H. pylori expresses a Fur homolog, which functions as an iron-dependent transcriptional repressor [12-15]. Recently it was demonstrated that Fur binds to the promoters of the iron-repressed HP0876 frpB gene [14] and the iron-induced $p f r$ gene $[13,15]$. In this study we have established the role of the $H$. pylori Fur protein in regulation of iron uptake, by determining the effects of fur mutation in $H$. pylori on rates of iron uptake and on transcription of the comprehensive set of iron uptake genes of H. pylori.

\section{Methods}

\section{Bacterial Strains, Plasmids, Media and Growth Conditions.}

H. pylori strains used in this study were the wild-type strains 1061 [16], 26695 [8], NCTC 11638 (National Collection of Type Cultures), and their respective isogenic fur mutants $[3,13,17]$. H. pylori strains were routinely cultured on Dent agar [18], consisting of Columbia agar supplemented with 7\% saponin lysed horse blood, $0.004 \%$ triphenyltetrazolium chloride (Sigma, St Louis, MO) and Dent Selective Supplement (Oxoid, Basingstoke, UK), at $37^{\circ} \mathrm{C}$ under microaerophilic conditions $\left(10 \% \mathrm{CO}_{2}, 5 \% \mathrm{O}_{2}\right.$ and $85 \% \mathrm{~N}_{2}$ ). Broth cultures were grown in Brucella Broth (Difco BD, Sparks, MO) supplemented with 3\% Newborn Calf Serum (Gibco Life Techn., Breda, NL) (BBN). $\mathrm{FeCl}_{3}$ (ACS quality) and desferal (deferoxamine mesylate) were purchased from Sigma, filter sterilised and used at the indicated concentrations. Iron-restriction was achieved by supplementing BBN with desferal to a final concentration of $20 \mu \mathrm{M}$, whereas iron-replete conditions were achieved by supplementing desferaltreated $\mathrm{BBN}$ with $\mathrm{FeCl}_{3}$ to a final concentration of $100 \mu \mathrm{M}$. E. coli strains were grown aerobically in Luria-Bertani medium at $37^{\circ} \mathrm{C}$ [19]. For antibiotic selection, growth media were supplemented with ampicillin, kanamycin, or chloramphenicol to final concentrations of $100 \mu \mathrm{g} / \mathrm{ml}$, $20 \mu \mathrm{g} / \mathrm{ml}$ and $10 \mu \mathrm{g} / \mathrm{ml}$, respectively.

\section{Iron Transport and Whole-Cell Iron Content Analysis}

The uptake rates of ferrous iron and ferric iron were determined using ${ }^{55} \mathrm{Fe}$ as described previously [11]. For uptake assays, ferric iron was obtained by diluting ${ }^{55} \mathrm{FeCl}_{3}$ ten-fold in $1 \mathrm{M}$ sodium citrate, while ferrous iron was obtained by tenfold dilution of ${ }^{55} \mathrm{FeCl}_{3}$ in $1 \mathrm{M}$ ascorbate. Analysis of whole cell iron content was performed using atomic absorption spectroscopy as described previously [11].

\section{Recombinant DNA Techniques}

Restriction enzymes and modifying enzymes were purchased from New England Biolabs (Beverly, MA) and Promega (Madison, WI), and standard protocols were used for manipulation of DNA and transformation of E. coli [19] and H. pylori [20]. Plasmid DNA was prepared using Qiaprep spin columns (Qiagen, Valencia, Spain). PCR was carried out using Taq polymerase (Promega).

\section{RNA Hybridization}

RNA was isolated from bacteria grown in ironrestricted or iron-replete conditions using RNeasy spincolumns (Qiagen) or Trizol (Gibco) according to the manufacturer's instructions. RNA was directly transferred to nylon membranes (Roche, Basel, Switzerland) using a Bio-Dot microfiltration 
Table I Genes and their proposed functions, and corresponding oligonucleotides used in this study

\begin{tabular}{lllll}
\hline Gene & Numbera & (Proposed) Function & Forward primer $\left(5^{\prime} \rightarrow 3^{\prime}\right)$ & T7-tagged reverse primer $\left(5^{\prime} \rightarrow 3^{\prime}\right){ }^{b}$ \\
\hline fecAI & HP0686 & Outer membrane siderophore receptor & CTCGCACGGTGATTTCTAAC & T7-TTAGGGCCATAACGCACGCT \\
fecA2 & HP0807 & Outer membrane siderophore receptor & AAGCTCTCGCACGGTGATTT & T7-AAGTGTTAGGGCCGTATTGG \\
fecA3 & HPI400 & Outer membrane siderophore receptor & GATTACCGCGCCTAAGAGTT & T7-CTGCCTCCACCCTTGATCAC \\
frpBI & HP0876 & Outer membrane siderophore receptor & TCAACGCCAAAGCAATGAAG & T7-GGCTCTTTATCGGTCTGTGT \\
frpB2/3 & HP0916/5c & Outer membrane siderophore receptor & AGAAGGCAAGCCAACCAAAT & T7-CCCACTTATGGCGTAGTCTT \\
frpB4 & HPI5I2 & Outer membrane siderophore receptor & AGCCGTCTCTTAAGGGTAAC & T7-TCGCTATTGCTTGGATCTTG \\
ceuEI & HPI562 & Iron-transport periplasmic binding protein & AAGTGCCTGCCATGCTTAAT & T7-CTCTGCAATCGTTGTCTCTT \\
ceuE2 & HPI56I & Iron-transport periplasmic binding protein & ACTTGGG/TAGCTTTGCAGAA & T7-GCTTGAGCGTCAATATCTTC \\
fecD & HP0889 & Cytoplasmic membrane permease & ATAGCGGTAGTGGAGTCTAA & T7-CGCAACAGCACCGGGTTAAT \\
fecE & HP0888 & Cytoplasmic membrane ATPase & GCGCTTGGATTTAGAGTCCT & T7-TGGCAACCAAATTCGGATCA \\
feoB & HP0687 & Cytoplasmic membrane Fe ${ }^{2+}$ transporter & ACTTACGCGCTCAATGACTT & T7-AGCCTGACAATTTCGTCTAA \\
pfr & HP0653 & Ferritin iron storage protein & N/Ad & N/A \\
nap & HP0243 & Bacterioferritin/DNA-binding protein & TGCATAAAGCCACTGAAGAA & T7-TCATCCGCATAAGTTACGGT \\
\hline
\end{tabular}

aGene number in the Helicobacter pylori 26695 genome sequence.

bPrimers contained a $5^{\prime}$-extension with T7 promoter sequence ( $5^{\prime}$-ctaatacgactcactatagggaga-), for the creation of an antisense RNA probe. cHP0916/09I5 are two separate ORFs in H. pylori 26695, but comprise one ORF in H. pylori 99 [8,9].

dProbe was prepared using the SP6 promoter on plasmid PPFRI [22].

Table 2 Transcriptional lacZ fusions of Helicobacter pylori frpB and fecA OM receptor genes

\begin{tabular}{lccc}
\hline & & \multicolumn{2}{c}{$\beta$-galactosidase activity in } \\
\cline { 3 - 4 } Gene & Position promoterc & wildtype strain & fur mutant $^{\text {d }}$ \\
\hline fecAl (HP0686) & $73829 I-736905$ & $14 \pm 4$ & $106 \pm 18^{*}$ \\
fecA2 (HP0807) & $863754-862623$ & $1 \pm 1$ & $40 \pm 26^{*}$ \\
fecA3 (HPI400) & $1460556-1461748$ & $256 \pm 59$ & $262 \pm 24$ \\
frpBI (HP0876) & $926943-927679$ & $2 \pm 2$ & $50 \pm 5^{*}$ \\
frpB2 (HPO9I6) & $974334-973127$ & $10 \pm 3$ & $25 \pm 6^{*}$ \\
frpB4 (HPI5I2) & $1584242-1585207$ & $10 \pm 4$ & $14 \pm 4$ \\
\hline
\end{tabular}

a $\beta$-galactosidase activity is expressed in Miller units [19]. Asterisks indicate a significant difference in $\beta$-galactosidase activity in the fur mutant strain, when compared with the activity in the wild-type strain ( $p<.0$ I, Student's $t$-test, $\mathrm{n}=5-7$ ).

bHP gene numbers corresponding to the $H$. pylori 26695 genome sequence [8].

cPosition of duplicated fragment fused to the $\mathrm{PBW}$ lacZ gene, corresponding to the H. pylori 26695 genome sequence [8].

$d H$. pylori strains used were $106 \mathrm{I}[16]$ and its isogenic fur mutant $[3,17]$.

apparatus (Bio-Rad, Hercules, CA) [17,19]. Following transfer, RNA was covalently bound to the membrane by cross-linking with $0.120 \mathrm{~J} /$ $\mathrm{cm}^{2} \mathrm{UV}$ light of $254 \mathrm{~nm}$ wavelength. RNA samples were normalized based on $16 \mathrm{~S}$ and $23 \mathrm{~S}$ rRNA band intensities.

Internal fragments of target genes were PCR amplified with primers listed in Table 1 . The resulting PCR fragments, which were all of a size between 200 and $400 \mathrm{bp}$, contained a T7 promoter sequence and were used for the production of antisense RNA probes labeled with digoxigenin by in vitro transcription using T7 RNA polymerase (Roche) [17]. Northern hybridization and stringency washes were performed at $68^{\circ} \mathrm{C}$, and bound probe was visualized with the DIG-Detection Kit (Roche) and the chemiluminescent substrate CPD-Star (Amersham Pharmacia, Roosendaal, NL).

\section{Construction of Transcriptional lacZ Fusions in H. pylori}

DNA fragments containing the predicted promoter regions of all $f e c A$ and $f r p B$ genes in the $H$. pylori 26695 genome were amplified by PCR using primers designed from the 26695 genome sequence. The exact position of the DNA fragment is given in Table 2. The PCR fragments were cloned into the unique $B g l$ II site upstream of the promoterless lac $Z$ gene of vector $\mathrm{pBW}$ $[17,21]$, and the resulting plasmids were transformed to $H$. pylori 1061 and 1061 fur as described previously [20], resulting in kanamycin-resistant $H$. pylori strains. $\beta$-galactosidase activity of these strains was determined in lysates from freshly sonicated cells as described previously $[17,19]$, and $\beta$-galactosidase activity was expressed in Miller units [19]. 

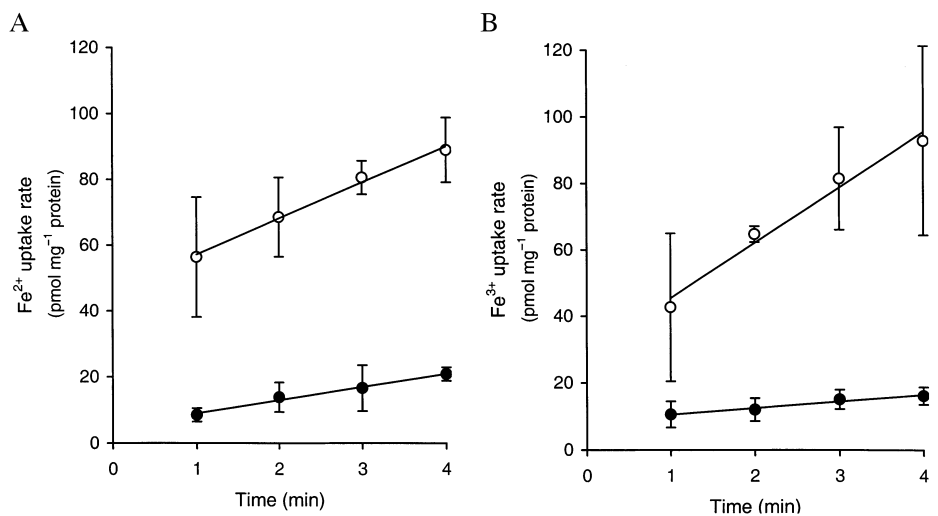

Figure I Iron uptake is increased in a Helicobacter pylori fur mutant. Rates of ferrous and ferric iron uptake in $H$. pylori wild-type and fur mutant were determined after transport was initiated with ${ }^{55} \mathrm{Fe}^{2+}(\mathrm{A})$ or $55 \mathrm{Fe}^{3+}$ dicitrate (B) to cell suspensions of H. pylori NCTC II 638 wild-type (O) and fur mutant $(\bigcirc)$ cells. The graphs show the average of results of three independent experiments.

\section{Results}

Effect of the fur Mutation on Iron Uptake and Whole Cell Iron Content

The effect of the fur mutation on ferrous and ferric iron uptake rates of $H$. pylori was studied using ${ }^{55} \mathrm{Fe}$ in wild-type and fur mutant cells. Uptake rates of ferrous iron and ferric iron uptake were clearly increased in the fur mutant when compared with the wild-type strain (Figure 1). The increase was approximately four-fold for ferrous iron and six-fold for ferric iron, indicating that repression of iron uptake was absent in the fur mutant. Similar results were obtained with the $H$. pylori strain 26695 and its isogenic fur mutant (data not shown). Increased iron uptake as a result of fur mutation resulted in an increase in the whole cell iron content of the fur mutant $(1.1074 \%$ iron of total dry weight) compared with the wild-type strain $(0.2986 \%$ iron of total dry weight).

\section{Transcriptional Analysis of $\mathrm{H}$. pylori Iron Transport and Storage Systems}

The H.pylori 26695 genome sequence contains 13 genes encoding putative components of $H$. pylori iron transport or iron storage systems (Table 1) [8]. Antisense RNA probes of these 13 genes were created, and hybridized with RNA isolated from $H$. pylori wild-type and fur mutant cells grown in iron-restricted and in iron-repleted conditions. Iron-responsive and Fur-mediated regulation was identified by visually comparing intensities of hybridization signals in the wildtype and fur mutant cells grown under different iron conditions (Figure 2).

Transcription of the $f e c A 1, f e c A 2, f r p B 1$ and frp $B 2$ genes was iron-repressed in wild-type cells, but derepressed in the fur mutant (Figure 2), indicating Fur-regulation of these genes. This confirms the previously reported Fur-mediated regulation of the $f_{r p} B 1$ gene $[14,15]$. Surprisingly, transcription of the $f e c A 3$ and $f r p B 4$ genes was not affected by changes in either iron concentration or the absence of Fur (Figure 2). Transcription of the $f e o B$ gene was also iron- and Fur-repressed (Figure 2). Transcription of the genes encoding the components of a cytoplasmic ABC-transporter (ceuE1, ceuE2, fecD and fecE genes) was not repressed by iron, and also not affected by the fur mutation (Figure 2). As controls we also hybridized the RNA samples with probes specific for the iron storage genes $p f r$ and napA [15,22-24]. The transcriptional patterns obtained corresponded with those reported previously: transcription of $p f r$ was iron-induced, Furdependent (Figure 2) [13,15], whereas transcription of napA was not affected by iron or the fur mutation (Figure 2) [24]. Results obtained using slotblotted RNA were confirmed by Northern hybridization (data not shown), although only mRNA species smaller than $1 \mathrm{~kb}$ remained intact. Especially $f e c A$ and $f r p B$ mRNAs were prone to degradation, resulting in smears with the maximum size of the hybridizing RNA smear of the predicted size based on analysis of the $H$. pylori genome sequence [8].

\section{Regulation of fecA and frpB Genes is Mediated via their Respective Promoter Regions}

Chromosomal transcriptional lacZ fusion $[17,21]$ was used to confirm the transcriptional regulation demonstrated by RNA hybridization and to locate the corresponding promoter regions. These transcriptional fusions would also allow us to determine whether the observed regulation results from true transcriptional regulation (changes in de novo mRNA synthesis), or altered 


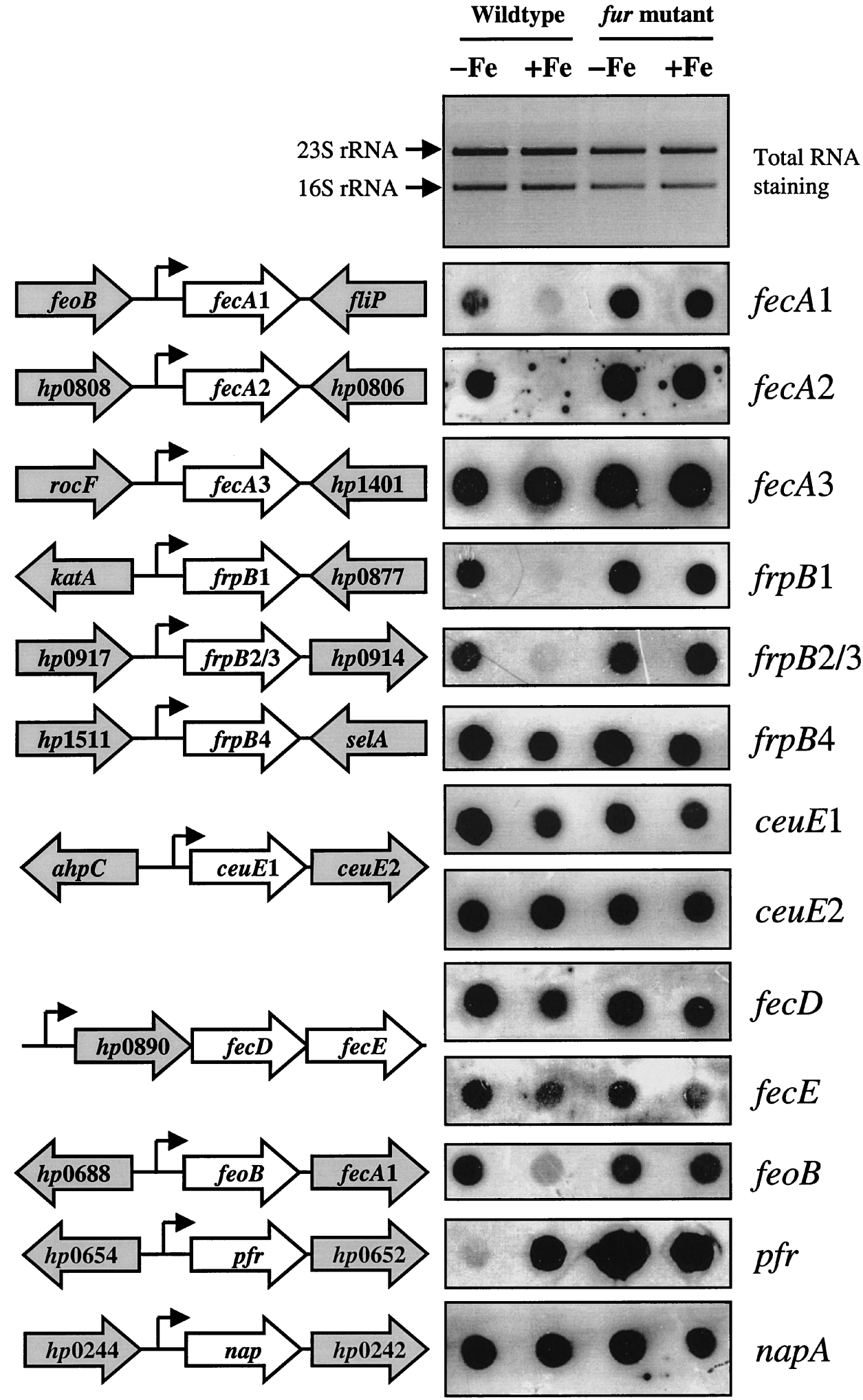

Figure 2 Transcriptional analysis of Helicobacter pylori 26695 iron transport and storage genes. Spotblot hybridization with probes specific for 13 putative iron acquisition and iron storage genes, using RNA purified from $H$. pylori wild-type and fur mutant cells grown in iron-restricted $(-\mathrm{Fe})$ and iron-replete $(+\mathrm{Fe})$ conditions. Probes used are indicated on the right, transcriptional organization and predicted location of the promoter of the corresponding gene is indicated on the left. Staining of transferred RNA by methylene blue is included for comparison of RNA amounts. 
mRNA stability. The intergenic regions preceding all $f e c A$ and $f r p B$ genes were amplified by PCR, cloned in the correct orientation in front of the promoterless lac $Z$ gene of $\mathrm{pBW}$ and transformed into H. pylori 1061 and 1061 fur. Integration of the $\mathrm{pBW}$ derivatives into the $H$. pylori chromosome by single homologous recombination leads to kanamycin resistance $[17,21]$ and the duplication of the inserted DNA fragment, with one copy of the promoter fused to the promoterless lac $Z$ gene and the other copy still preceding the intact gene $[17,21]$. As shown in Table 2 , the $\beta$-galactosidase activities reflected the patterns of regulation shown by RNA hybridization; expression of the $f e c A 1, f e c A 2$, $\operatorname{frp} B 1$ and $\operatorname{frp} B 2$ lac $Z$ fusions is repressed in H. pylori 1061, whereas in the absence of Fur expression is significantly increased (Table 2). In contrast, expression of the fecA3 and frpB 4 lac $Z$ fusions is not significantly affected by the fur mutation (Table 2).

\section{Discussion}

The varying and harsh conditions predicted to occur in the gastric mucosa have necessitated the development of adaptive mechanisms for $H$. pylori, and these are often mediated via gene regulation. Based on analysis of the complete genome sequences, it was predicted that $H$. pylori has a relatively limited capacity for gene regulation [8-10]. There are only three sigma factors, and homologs of bacterial global regulators such as RpoS, OxyR and SoxRS are absent [8-10]. One of the few global regulators present in H. pylori is the Fur protein $[13,14,17,25]$. The best studied function of Fur in bacteria is its control of iron transport [2], but in $H$. pylori Fur not only regulates iron uptake (this study and $[14])$, but also regulates iron storage $[13,15]$, modulates urease expression in response to nickel [17], and is required for full acid resistance of H. pylori [3].

The transcriptional analysis of iron transport and iron storage genes suggests that $H$. pylori expresses iron transport systems in iron-replete conditions, but when exposed to iron-restriction, expresses additional iron transporters. This is in contrast to other bacteria, which only express iron uptake proteins when exposed to ironrestriction, since derepressed uptake of iron often leads to toxicity [1]. Confirmation for the mRNA studies was obtained using genomic transcriptional lacZ fusions in H.pylori strain
$1061[17,21]$ (Table 2). Since the use of the pBW-system is currently restricted to $H$. pylori strain 1061 [21], this also confirms that the transcriptional patterns are conserved between two different $H$. pylori strains, and are possibly also present in other $H$. pylori strains.

On the basis of our transcriptional analysis, the complement of genes expressed by $H$. pylori under iron-replete and iron-restricted conditions is summarized in Figure 3. In iron-replete environments, $H$. pylori expresses a single FecA and FrpB outer membrane protein, both $\mathrm{CeuE}$ periplasmic binding proteins, the FecDE $\mathrm{ABC}$ transporter proteins, the $\mathrm{Pfr}$ ferritin and the NapA protein. In iron-restricted conditions, all putative iron transport proteins are expressed, including the remaining two FecA and two FrpB outer membrane proteins, and the FeoB protein. Conversely, expression of the Pfr ferritin is decreased upon iron-restriction $[13,15,24]$. This model is consistent with the low but constitutive levels of iron transport in the wild-type strain, and the increased rates of iron transport (Figure 1) and increased whole cell iron content of the fur mutant. It may be possible to utilize the constitutive iron transport of $H$. pylori for the development of new antimicrobials, based on 'trojan-horse' noniron metalloporphyrins [26], but this requires further studies.

Compared with other bacteria, H. pylori can only utilize a relatively limited number of iron sources. All $H$. pylori strains tested can use ferric dicitrate, heme compounds and inorganic iron, while some strains might be able to utilize lactoferrin or transferrin [11,27-29]. Inconclusive results on $H$. pylori siderophore synthesis have been attributed to the ferric reductase activity of $H$. pylori, which is probably mediated via riboflavin synthesis [30]. Interestingly, $H$. pylori is much more sensitive to ferric dicitrate than to $\mathrm{FeCl}_{3}[11,22]$. This is consistent with the expression of $H$. pylori iron uptake systems as inferred from the transcriptional analysis (Figures 2 and 3 ). Ferric dicitrate is probably transported by the different components of the $H$. pylori Fec system, which can be composed of the constitutively expressed FecA3, CeuE and FecDE proteins, and their expression at moderate ferric-dicitrate concentrations may already lead to high intracellular iron concentrations, with associated toxicity [1].

In conclusion, the Fur protein plays a central role in iron-responsive gene regulation of $H$. pylori, since all iron-regulated genes identified so far 


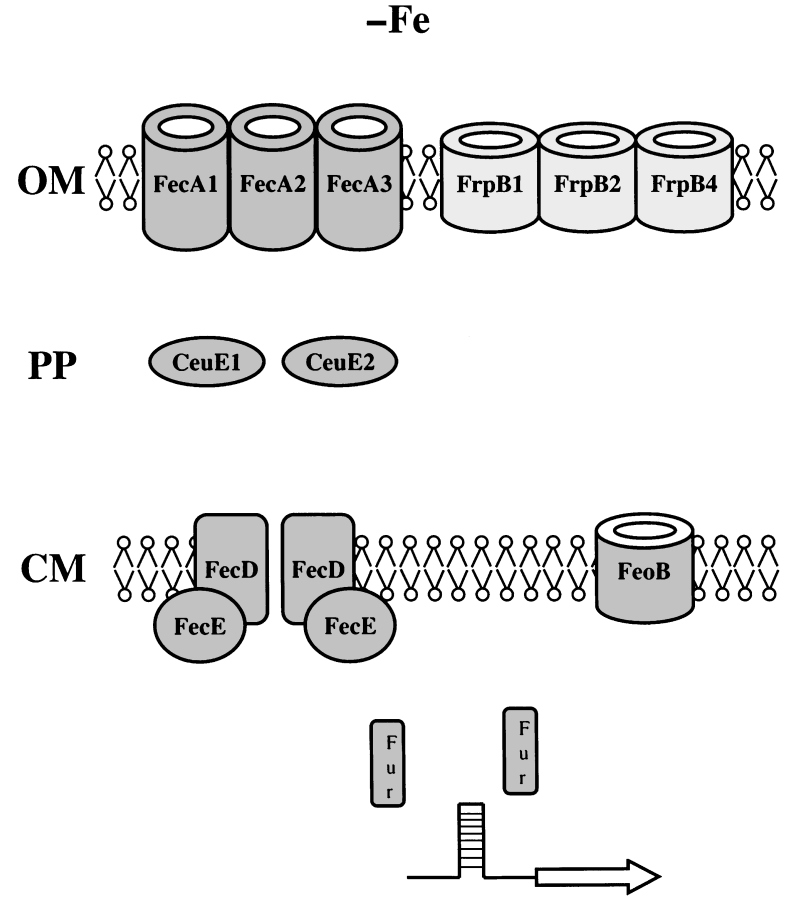

No Repression

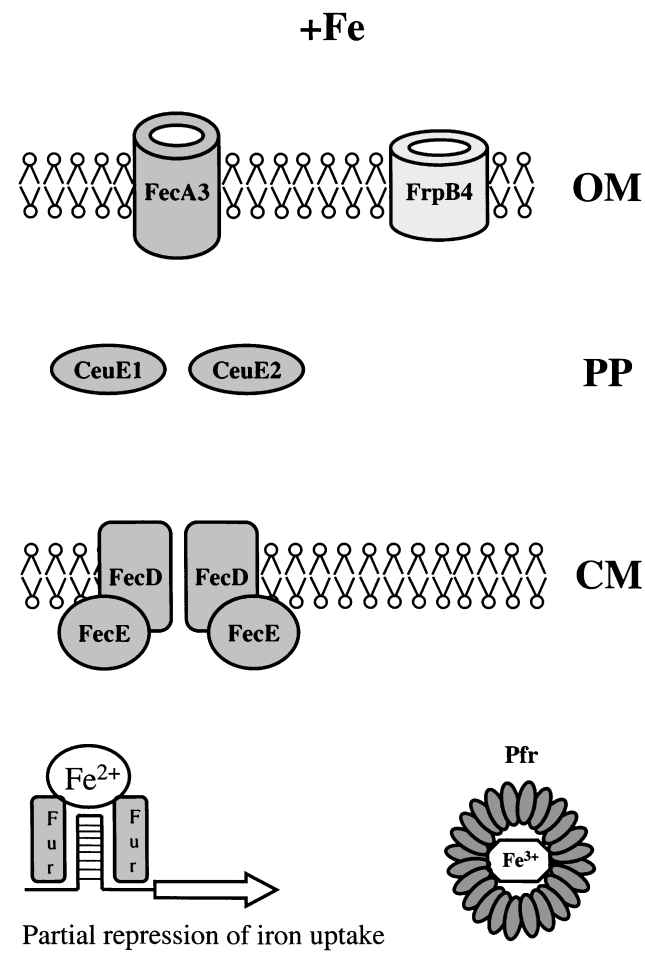

Figure 3 Schematic representation of regulation and predicted location of iron acquisition systems in Helicobacter pylori. -Fe: iron-restricted conditions; +Fe: iron-replete conditions; $\mathrm{OM}=$ outer membrane; $\mathrm{PP}=$ periplasm; $\mathrm{CM}=$ cytoplasmic membrane.

are regulated by Fur. However, in contrast to other bacteria, $H$. pylori does not down-regulate iron uptake in iron-replete conditions. Further studies are required to determine the role of Fur-mediated gene regulation in gastric colonization and inflammation, in identification of other members of the Fur regulon, and defining the binding sites of Fur in the promoters of its regulon.

We thank Raymond Pot and Theo Verboom for DNA sequencing, and Georg Homuth for helpful discussions.

This study was financially supported by grants from the Nederlandse Organisatie voor Wetenschappelijk Onderzoek to A.H.M.v.V. (901-14-206) and J.G.K. (DN93-340), the Deutsche Forschungsgemeinschaft (Ki201/9-1) to M.K., the UK Biotechnology and Biological Sciences Research Council to S.A.W., and the Wellcome Trust to D.J.K.

\section{References}

1 Touati D. Iron and oxidative stress in bacteria. Arch Biochem Biophys 2000;373:1-6.

2 Escolar L, Perez-Martin J, de Lorenzo V. Opening the iron-box: transcriptional metalloregulation by the Fur protein. J Bacteriol 1999;181:6223-9.
3 Bijlsma JJE, Waidner B, van Vliet AHM, et al. The Ferric Uptake Regulator (Fur) homolog of Helicobacter pylori is involved in acid resistance. Infect Immun 2002;70:606-11.

4 Hall HK, Foster JW. The role of fur in the acid tolerance response of Salmonella typhimurium is physiologically and genetically separable from its role in iron acquisition. J. Bacteriol 1996;178:5683-91.

5 Mobley HLT, Mendz GL, Hazell SL. Helicobacter pylori. Physiology and Genetics. Washington, DC: ASM Press, 2001.

6 Miehlke S, Reddy R, Osato MS, Ward PP, Conneely OM, Graham DY. Direct activity of recombinant human lactoferrin against Helicobacter pylori. J Clin Microbiol 1996;34:25934.

7 Braun V, Hantke K, Koster W. Bacterial iron transport: mechanisms, genetics, regulation $\mathrm{Met}$ Ions Biol Syst 1998;35:67-145.

8 Tomb JF, White O, Kerlavage AR, et al. The complete genome sequence of the gastric pathogen Helicobacter pylori. Nature 1997;388:539-47.

9 Alm RA, Ling LS, Moir DT, et al. Genomicsequence comparison of two unrelated isolates of the human gastric pathogen Helicobacter pylori. Nature 1999;397:176-80.

10 Berg DE, Hoffman PS, Appelmelk BJ, Kusters JG. The Helicobacter pylori genome sequence: genetic 
factors for long life in the gastric mucosa. Trends Microbiol 1997;5:468-74.

11 Velayudhan J, Hughes NJ, McColm AA, et al. Iron acquisition and virulence in Helicobacter pylori: a major role for $\mathrm{FeoB}$, a high-affinity ferrous iron transporter. Mol Microbiol 2000;37:274-86.

12 Fassbinder F, van Vliet AHM, Gimmel V, Kusters JG, Kist M, Bereswill S. Identification of iron-regulated genes of Helicobacter pylori by a modified Fur Titration Assay (FURTA-Hp). FEMS Microbiol Lett 2000;184:225-9.

13 Bereswill S, Greiner S, van Vliet AHM, et al. Regulation of ferritin-mediated cytoplasmic iron storage by the Ferric Uptake Regulator homolog (Fur) of Helicobacter pylori.J Bacteriol 2000;182:5948-53.

14 Delany I, Pacheco ABF, Spohn G, Rappuoli R, Scarlato V. Iron-dependent transcription of the frp $B$ gene of Helicobacter pylori is controlled by the Fur protein. J Bacteriol 2001;183:4932-7.

15 Delany I, Spohn G, Rappuoli R, Scarlato V. The Fur repressor controls transcription of ironactivated and - repressed genes in Helicobacter pylori. Mol Microbiol 2001;42:1297-309.

16 Goodwin A, Kersulyte D, Sisson G, Veldhuyzen van Zanten SJ, Berg DE, Hoffman PS. Metronidazole resistance in Helicobacter pylori is due to null mutations in a gene $(r d x A)$ that encodes an oxygen-insensitive NADPH nitroreductase. $\mathrm{Mol}$ Microbiol 1998;28:383-93.

17 van Vliet AHM, Kuipers EJ, Waidner B, et al. Nickel-responsive induction of urease expression in Helicobacter pylori is mediated at the transcriptional level. Infect Immun 2001;69:4891-7.

18 Dent JC, McNulty CA. Evaluation of a new selective medium for Campylobacter pylori. Eur J Clin Microbiol Infect Dis 1988;7:555-8.

19 Sambrook J, Fritsch EF, Maniatis T. Molecular Cloning, a Laboratory Manual, 2nd edn. Cold Spring Harbor, New York: Cold Spring. Harbor Laboratory Press, 1989.

20 Bijlsma JJE, Vandenbroucke-Grauls CMJE, Phadnis SH, Kusters JG. Identification of virulence genes of Helicobacter pylori by random insertion mutagenesis. Infect Immun 1999;67:2433-40.

21 de Vries N, Kuipers EJ, Kramer NE, et al. Identification of environmental stress-regulated genes in Helicobacter pylori by a lac $Z$ reporter gene fusion system. Helicobacter 2001;6:300-9.

22 Bereswill S, Waidner U, Odenbreit S, et al. Structural, functional and mutational analysis of the $p f r$ gene encoding a ferritin from Helicobacter pylori. Microbiology 1998;144:2505-16.

23 Tonello F, Dundon WG, Satin B, et al. The Helicobacter pylori neutrophil-activating protein is an iron-binding protein with dodecameric structure. Mol Microbiol 1999;34:238-46.

24 Dundon WG, Polenghi A, Del Guidice G, Rappuoli R, Montecucco C. Neutrophil-activating protein (HP-NAP) versus ferritin (Pfr): comparison of synthesis in Helicobacter pylori. FEMS Microbiol Lett 2001;199:143-9.

25 Bereswill S, Lichte F, Vey T, Fassbinder F, Kist M. Cloning and characterization of the fur gene from Helicobacter pylori. FEMS Microbiol Lett 1998;159:193-200.

26 Stojiljkovic I, Kumar V, Srinivasan N. Non-iron metalloporphyrins. Potent antibacterial compounds that exploit haem/Hb uptake systems of pathogenic bacteria. Mol Microbiol 1999;31:42942.

27 Worst DJ, Otto BR, de Graaff J. Iron-repressible outer membrane proteins of Helicobacter pylori involved in heme uptake. Infect Immun 1995;63:4161-5.

28 Dhaenens L, Szczebara F, Van Nieuwenhuyse S, Husson MO. Comparison of iron uptake in different Helicobacter species. Res Microbiol 1999;150:475-81.

29 Husson MO, Legrand D, Spik G, Leclerc H. Iron acquisition by Helicobacter pylori. importance of human lactoferrin. Infect Immun 1993;61:2694-7.

30 Worst DJ, Gerrits MM, Vandenbroucke-Grauls CMJE, Kusters JG. Helicobacter pylori ribBAmediated riboflavin production is involved in iron acquisition. J Bacteriol 1998;180:1473-9. 